\title{
Aproximación al proceso migratorio venezolano en el siglo XXI*
}

\author{
Manuel Felipe García Arias** \\ Jair Eduardo Restrepo Pineda ${ }^{* * *}$
}

Recibido: 5 de octubre del 2018

Evaluado: 11 de octubre de 2018

Aceptado: 26 de noviembre del 2018

Citar cómo: García Arias, M. F. y Restrepo Pineda J. E. (2019). Aproximación al proceso migratorio venezolano en el siglo XXI. Hallazgos, 16(32), 63-82. DOl: https://doi. org/10.15332/2422409X.5000

\section{Resumen}

Este artículo tiene como objetivo realizar una revisión documental sobre la producción académica y científica que del proceso migratorio venezolano se ha generado a partir del año $2000 \mathrm{y}$ hasta la fecha, bajo un análisis documental de fuentes secundarias. Se evidencia que el estudio de la dinámica migratoria latinoamericana es complejo y las diferentes teorías que tratan de explicarla suelen incluir variables tales como la transición demográfica, la globalización de los medios de comunicación, la dependencia cultural, las redes familiares que se relacionan con las dificultades que estos países han experimentado, afectando el empleo, el salario real y la seguridad económica y, en consecuencia, generando estímulos para migrar. El análisis de la emigración venezolana permite conocer este proceso y la edificación de un "territorio otro" como un lugar oportuno para la controversia de las identidades nacionales y para la escritura de las relaciones entre sujetos migrantes y sus entornos socioculturales.

Palabras clave: emigración, migración internacional, Venezuela.

* El artículo hace parte de la investigación titulada: Análisis del proceso de inmigración de los venezolanos a Bogotá D. C. y a las áreas metropolitanas de Cúcuta y Medellín, financiado por la Dirección General de Investigaciones de la Corporación Universitaria Minuto de Dios - Uniminuto.

* Especialista en Familia, Infancia y Adolescencia. Corporación Universitaria Minuto de Dios - Uniminuto. Bello, Antioquia, Colombia. Correo electrónico: manuel.garcia-a@uniminuto.edu.co - ORCID: https://orcid.org/0000-0001-5198-7405

** Doctor en Análisis y Evaluación de Procesos Políticos y Sociales. Corporación Universitaria Minuto de Dios - Uniminuto. Bello, Antioquia, Colombia. Correo electrónico: jair.restrepo@unimintuo.edu.co - ORCID: https://orcid.org/0000-0002-3959-4550 


\section{Approach to the Venezuelan migratory process in the 21st century}

\section{Abstract}

The objective of this article is to conduct a documentary review Received: october 5,2018 of the academic and scientific production that has been geneEvaluated: october 11, 2018 rated from the Venezuelan migratory process from the year 2000 to the present, under a documentary analysis of secondary sources. It is evident that the study of Latin American migratory dynamics is complex and the different theories that have tried to explain it usually include variables such as the demographic transition, the globalization of the media, the cultural dependence and the family networks that are related to the difficulties that these countries have experienced, and have affected employment, real income and economic security, which consequently have incentivized people to migrate. The analysis of the Venezuelan emigration, allows to know this process and the construction of an "other territory" as an appropriate place for controversy of the national identities and for the writing of the relations between migrant individuals and their sociocultural environments.

Keywords: Emigration, international migration, Venezuela. 


\section{Aproximação ao processo migratório venezuelano no século XX}

Recebido: 5 de outubro de 2018

Avaliado: 11 de outubro de 2018

Aceito: 26 de novembro de 2018

\section{Resumo}

Este artigo tem como objetivo realizar uma revisão documental sobre a produção acadêmica e cientifica que do processo migratório venezuelano se tem gerado a partir do ano 2000 e até agora sob uma análise documental de fontes secundarias. Evidencia-se que o estudo da dinâmica migratória latino-americana é complexo e as diferentes teorias que tratam de explicá-la costumam incluir variáveis tais como a transição demográfica, a globalização da mídia, a dependência cultural, as redes familiares que se relacionam com as dificuldades que estes países têm experimentado, afetando o emprego, o salário real e a segurança econômica e, em consequência, gerando estímulos para migrar. A análise da migração venezuelana permite conhecer este processo e a edificação de um "território outro" como um lugar apropriado para a controvérsia das identidades nacionais e para a escritura das relações entre sujeitos migrantes e seus ambientes socioculturais Palavras-chave: emigração, migração internacional, Venezuela. 


\section{INTRODUCCIÓN}

La emigración venezolana del siglo XXI personifica un prodigio histórico, social, político y económico que resultará palpable en la historia venidera. Del acoplamiento de los movimientos migratorios surge una naciente pero firme inquietud sobre las grafías que se producen, fruto de este desplazamiento transnacional que ha transformado por completo la demografía nacional de Venezuela. Este análisis cualitativo se ha propuesto hacer una recopilación documental, de las principales ilustraciones sobre el caso de la emigración venezolana en el presente siglo. En el primer momento de este análisis se abordan las definiciones, causas y consecuencias de las migraciones en general, especulando que la migración como prodigio multifacético se exhibe como una peculiaridad significativa en las disímiles etapas históricas de la humanidad, tanto en el aspecto demográfico como en el económico, no dejando de lado sus indiscutibles efectos sobre la configuración social y cultural de un país. En el segundo momento, se exponen algunos de los enfoques teóricos con los que se ha vinculado la migración, ilustrando la clasificación elaborada por el Colectivo Ioé. En el tercer momento, se aborda la elaboración metodológica de esta investigación documental que fue perfilada a partir de un enfoque cualitativo y sincrónico. En cuarto lugar, se establece una vinculación entre los conceptos de migración y familia, vista como una relación de permutación que es percibida como una estrategia familiar. En el quinto momento, y el más importante, se expone la recopilación documental de los trabajos en torno a la emigración venezolana en el siglo XXI, dando cuenta de que, si bien la escritura de procesos migratorios en la literatura venezolana contemporánea se había condensado casi exclusivamente en la inmigración, en los últimos años asistimos al apogeo de narraciones sobre sujetos emigrantes que concuerdan con el desplazamiento masivo de venezolanos de la última década. En el último momento se encuentran las conclusiones, en donde a partir de los documentos revisados, planteamos que la emigración ha generado el tráfico de personas y familias de un contexto cultural a otro, concentrando una cadena de narraciones que registran la trasformación de las redes sociales, culturales e identitarias, las necesidades económicas, la xenofobia, el racismo y la construcción de un espacio liminal que ocupan los venezolanos llegados en la sociedad de recepción.

\section{DEFINICIONES, CAUSAS Y CONSECUENCIAS DE LAS MIGRACIONES}

Cuando pensamos en el término migración, nos encontramos con que este ostenta disímiles usos y aplicaciones dependiendo de las áreas y cuestiones de estudio, es decir, este se inserta en un contexto concreto, lo que hace que debamos hallar diferentes aproximaciones, análisis y escenarios que permitan entender de manera apropiada el concepto. Como lo plantea Echeverry (2012), “en general, las migraciones son una condición dada por necesidades de tipo biológico, económico, social, cultural, etc., de encontrar lugares, entornos, ambientes y sistemas que puedan suplir esas necesidades originales" (p. 13).

La Organización Mundial de la Salud determina la migración como "el movimiento de una persona o grupo de personas de una 
unidad geográfica hacia otra a través de una frontera administrativa o política con la intención de establecerse de manera indefinida o temporal en un lugar distinto a su lugar de origen" (OMS, 2016, citado por Pacheco, 2016, p. 18). Por su parte, la definición de Kearney Bernadete (2002) precisa la migración como "un movimiento que atraviesa una frontera significativa que es definida y mantenida por cierto régimen político: un orden formal o informal de tal manera que afecta la identidad del individuo" (citado por Martínez Casadiegos, 2016, p. 44). En ambas definiciones aparece la noción de frontera como elemento consustancial que entreteje o posibilita el direccionamiento del proceso de migración.

De otro lado, Puyol (1990) plantea que "la migración es un conjunto de movimientos que tienen por objeto trasladar la residencia de las personas interesadas de un lugar de origen a otro de destino. Una migración supone siempre el desplazamiento de un grupo importante de personas" (citado por Martínez Casadiegos, 2016, p. 44). Por su parte, Delgado (2007) entiende la migración como "todas las maneras con que los ciudadanos de cualquier nación satisfacen la siempre existente necesidad de cambiar de lugar de residencia" (p. 197). En tanto, para Bauböck la migración es entendible como la "relocalización de individuos entre Estados-nación" (citado por Rivas, 2004, p. 194) los cuales entrelazan un rol significativo, no únicamente al conformar los esquemas migratorios, sino cuando intervienen en los tipos, magnitudes y densidades de los tejidos sociales de los migrantes.

A partir de las definiciones anteriores, podríamos decir que la migración como prodigio multifacético se exhibe como una peculiaridad significativa en las disímiles etapas históricas de la humanidad, tanto en el aspecto demográfico como en el económico, no dejando de lado sus indiscutibles efectos sobre la configuración social y cultural de un país. Dentro de las causas que pueden llegar a impulsar su configuración se encuentran las físicas y las humanas. Entre las primeras se hallan las catástrofes naturales: terremotos, erupciones volcánicas, ciclones, sequías y malas cosechas. Entre las segundas se encuentran principalmente las políticas, religiosas y económicas. Sin dejar de lado las motivaciones en razón de la guerra y los conflictos sociales. En todo caso -en la contemporaneidad-, la causa más importante por lo que las personas migran está relacionada con el factor económico. Existe un tercer componente dentro de las causas de migrar, que se produce cuando individuos emigrados regresan pasado un tiempo a su lugar de origen, denominándoseles "retornados" (Echeverry, 2012).

En la segunda mitad del siglo XX tres grandes patrones migratorios marcaron el mapa regional de América Latina; la inmigración de ultramar muestra la acostumbrada afinidad ejercida por la región sobre la población de otras superficies del mundo, consolidando el primero de estos patrones. El segundo, cuya permanencia está hondamente anclada en la historia, resulta del intercambio recíproco de población entre los propios países de la región. El tercero, es el de la emigración hacia el exterior de América Latina y el Caribe, cuya progresiva intensidad parece mostrar señales de expulsión (Villa y Martínez, 2001).

En la actualidad vivimos en una época que algunos analistas han calificado como la nueva era de la migración, debido al 
impacto de la innegable primacía del factor económico como causa de la salida de muchas personas de sus países de origen, además de los factores tanto sociales como políticos (Sandell, Sorroza y Olivié, 2007). La búsqueda de un oficio que se suponga digno bajo las medidas de la Organización Internacional del Trabajo (OIT), es una de las primordiales razones que incitan hoy día a muchos trabajadores a emigrar gracias al alto índice de inactividad y a la precariedad laboral a la que se ven sometidos fruto de realizar tareas en las que en muchas ocasiones son subpagados y explotados.

Es una situación indiscutible que millones de sujetos en el mundo se desplazan cada año de sus países de origen en busca de trabajo, pues su anhelo es el de "ingresar a un trabajo que provea las condiciones para el desarrollo personal, profesional y el sustento necesario para un mínimo de bienestar" (Lucena, 2007, p. 8). La migración laboral, entendida como la movilización de trabajadores de un país a otro en busca tanto de mejores condiciones de trabajo como de mayores ingresos económicos, se ha convertido en factor determinante y de gran impacto en la economía mundial debido a las grandes cantidades de remesas que cada año envían a sus países de origen los trabajadores migrantes, contribuyendo tanto al crecimiento económico de estos, así como al sostenimiento de sus propias familias (Delgado y Abellana, 2009; Oso Casas y Villares Varela, 2005).

En la dinámica de la demografía internacional, se plantea que los procesos migratorios se presentan a partir de dos tipos de surgimientos: aquel que nace de factores de expulsión y el que brota de factores de atracción. Tanto en los unos como en los otros aparecen fenómenos sociales, políticos, de violencia o económicos. Respecto a estos últimos puede afirmarse que, con la globalización, los países -sobre todo los latinoamericanos- han perdido el grado de autonomía al diseñar su política económica, pues no pueden actuar libremente sobre importantes variables como los tipos de cambio o sobre los tipos de interés (Martínez Casadiegos, 2016). Es por ello que las oleadas migratorias se originan desde los países con niveles de vida, salarios, oportunidades laborales y grados de tranquilidad social y estabilidad política (de Flores, 2009) comparativamente más desfavorables, hacia otros, con posibilidades más favorables.

Podríamos afirmar que la intención migratoria de colombianos y venezolanos además en lo que tiene que ver con cualquier ciudadano migrante se basa principalmente por razones de tipo políticas, económicas y culturales. En referencia de las primeras razones podríamos afirmar que no precisamente nos estamos refiriendo a persecuciones propiamente del Estado de origen y en contra del migrante sino simplemente a las pocas garantías y condiciones ofrecidas por el país de origen del ciudadano que decide salir de su país $\mathrm{y}$ asentarse en un nuevo Estado, las cuestiones económicas desde nuestra óptica pueden considerarse con las razones de mayor escala en la intención del ciudadano migrante en la medida en que consideran que el país de origen no ofrece las garantías laborales con las cuales se pueda desarrollar bajo el concepto de una vida digna, en este sentido es importante considerar que si el país emisor atraviesa circunstancias 
de crisis, los ciudadanos menos protegidos por este, dentro de sus posibilidades probablemente decidirán migrar a otro país receptor. (Martínez Casadiegos, 2016, p. 32).

Las dificultades económicas que han originado el transcurso migratorio, que mucho tienen que ver con la frágil justicia social, el desempleo, la desigualdad de oportunidades, la libertad de expresión o no, la vigencia de una verdadera democracia y la primacía del bien común, son al parecer muestra de que los diferentes escenarios de hambre, miseria y la evidente falta de oportunidades en varios países obliga a una importante cantidad de sus oriundos a convertirse en emigrantes, en muchos casos irregulares (Di Brienza, 1997), que arriesgan sus vidas, con tal de salir de las precarias condiciones que ofrece el país de origen.

Por otra parte, las migraciones afectan en diferentes aspectos (sociales y económicos) tanto a los territorios de origen como a los de destino; las consecuencias más importantes son, como lo establece Echeverry (2012):

\section{Demográficas}

- La población emigrante suele ser joven, en edad de trabajar y procrear, por lo que los destinos se rejuvenecen, mientras que el origen envejece al quedar los efectivos poblacionales más mayores, que ya no procrean. No obstante, para nuestro caso, es vital mencionar que mucha de esa migración venezolana también se da por anteriores migrantes colombianos establecidos en el país bolivariano hace muchos años. Estamos hablando entonces de migraciones de segunda y tercera generación, que pueden tener ascendencia colombiana (Echeverry, 2012).

- Desequilibrio de sexos. Es más común que emigren más hombres que mujeres, por lo que en el lugar de destino hay mayor proporción de hombres y en el de origen de mujeres.

- Un efecto más es el crecimiento desmesurado de las ciudades que acogen a la población emigrante del medio rural (Echeverry, 2012).

\section{Económicas}

- Los emigrantes envían parte de su sueldo en divisas al país de origen, con lo que se produce un ingreso económico importante para el desarrollo económico de esas naciones (ejemplo de ello se produjo en las últimas dos décadas en Colombia, en el que el sector de las remesas internacionales se ha convertido por momentos en el ingreso de primer renglón de la economía nacional), falta observar cuál es la situación de los venezolanos que envían remesas a su país; o si por el contrario, el tema de compensación económica, claramente beneficia al país receptor, en este caso, Colombia (Echeverry, 2012).

- Por otra parte, en el país de origen disminuye en cierto grado el estancamiento salarial, al marcharse parte de la población activa a otros lugares a trabajar, mientras que en el destino se abaratan los salarios por haber excesiva oferta de mano de obra.

- Se produce un incremento excesivo de las ciudades, en muchas ocasiones aumenta la población a mayor ritmo que 
el crecimiento de viviendas y de infraestructuras (Echeverry, 2012).

\section{Culturales}

- Las migraciones proporcionan la difusión de diferentes culturas a lo largo y ancho del mundo.

- Históricamente han servido para la difusión de avances científicos y sociales en otras partes del mundo (Echeverry, 2012).

\section{Sociales}

- Falta de integración de los emigrantes en el destino, debido a diferencias culturales muy grandes, como el idioma, la religión, etc.

- Desarraigo de los emigrantes de los lugares de origen, debido, por una parte, a la falta de contacto habitual y, por otra, a un intento de integración excesivo que les hace perder sus señas de identidad.

- En las sociedades de acogida suelen surgir sentimientos de rechazo hacia el emigrante, bien sea porque es forastero (xenofobia $u$ odio a lo extranjero) o bien por sus características físicas diferentes (racismo) (Echeverry, 2012).

\section{ENFOQUES TEÓRICOS DE LA MIGRACIÓN}

De los múltiples enfoques teóricos que existen sobre la migración, los cuales son tan amplios como complejos -en el sentido de que reúnen una serie de interpretaciones desde la economía, la política, lo religioso, lo cultural y social- es pertinente reseñar la clasificación elaborada por el Colectivo Ioé.

1. Enfoque individualista: entiende la migración como el resultado de libres decisiones de los individuos, por lo tanto, se enfoca en las motivaciones y expectativas, la convivencia en el marco del microcontexto. Este enfoque parte de la siguiente premisa “... las migraciones son un factor de equilibrio del mercado mundial, que se rige por el juego de la oferta y la demanda..." (Checa, 2002, pp. 39-40).

2. Enfoque histórico-estructural: considera la migración como parte de un sistema "... caracterizado como un conjunto dinámico, integrado por dos o más puntos -países, comarcas, regiones- vinculados por flujos humanos" (Checa, 2002, p. 41).

3. Enfoque integrado: propone una perspectiva amplia de la migración, que se valga, para su comprensión, de diferentes perspectivas entre las cuales se incluyen: análisis histórico, análisis estructural (economía política), análisis ideológico-cultural (discursos sociales) $\mathrm{y}$ de redes sociales migratorias (Checa, 2002).

\section{Metodología}

El artículo se elaboró a través de una revisión documental -análisis bibliográfico de fuentes secundarias: publicaciones, artículos de revista, libros, etc.- y fue perfilada a partir de un enfoque cualitativo y sincrónico. El diseño metodológico de este estudio se dividió en cinco momentos. El primer momento constó de la construcción y consolidación 
de las categorías de análisis: Venezuela, migración, emigración, familia, economía. El segundo momento tenía como finalidad la búsqueda de documentos que cumplieran con los siguientes criterios de selección: a) las categorías seleccionadas en el primer momento; b) que fueran investigaciones realizadas dentro de un rango de temporalidad que oscilará entre los últimos 18 y 23 años y, c) que fueran documentos donde se abordara el proceso migratorio latinoamericano con énfasis en el caso venezolano. El tercer momento permitió la elaboración de una matriz documental donde se recopilaron todos los textos que cumplieron con los criterios de selección expuestos en la segunda fase. Los documentos recopilados provienen de bases de datos indexadas, repositorios y directorios de revista (Proquest, Scopus, Ebsco, Dialnet, Jstor, Science Direct, Scielo, Redalyc, Web Of Science, Clacso, Doaj), que contienen información relevante, actualizada, precisa, contrastada y de calidad. El cuarto momento consistió en la operacionalización de las categorías de análisis, partiendo desde lo más general a lo más específico. En el quinto y último momento, se utilizó la información documental recogida, más la operacionalización realizada, para la sistematización y análisis de la información, dando como resultado dos tipos de estudios predominantes: a) estudios que examinan características sociodemográficas en función de los registros estadísticos o de la elaboración de encuestas, en las cuales se incluyen variables tales como: edad, sexo, estado civil, nivel educativo, profesión, ocupación, trayectoria laboral, relaciones de parentesco y otras relaciones $y, b$ ) estudios que indagan con mayor profundidad sobre las causas que llevan a las personas a emigrar de su país y las situaciones de vida que disfrutan, donde se exploran categorías como: el contexto migratorio, características familiares, redes de relaciones y su uso en situaciones difíciles, trabajo, vivienda, percepción del territorio, educación y lengua, e identidad cultural, entre otros.

\section{FAMILIA Y MigRACIÓN}

Se reconoce que el proceso migratorio tiene como origen y punto de partida la característica de asegurar la reproducción y sobrevivencia de la familia (Aguirre Ochoa y Cruz Vásquez, 2013). La familia es una de las instituciones sociales que, tocada por el influjo migratorio, exhibe mecanismos de reconfiguración social en puntos como la relación que mantiene la familia con sus integrantes migrantes, las formas que asume esta relación, los resultados que reflejan las nuevas formas imaginativas para sentirse familia durante la ausencia, sus cambios, sus adaptaciones socioculturales y más cuestiones internas (Aguirre Ochoa y Cruz Vásquez, 2013).

La migración internacional es una situación de gran complejidad jurídica, económica, política, social, demográfica y cultural que colma la superficie geográfica de las fronteras, por lo que afecta sin duda la estructura, funciones y dinámicas cotidianas de la familia. Debido a ello, algunos autores plantean que se ha venido revalorando el papel que la familia juega en la construcción de las relaciones sociales (Cozzani e Insa, 2011), como por ejemplo, en lo referido a las nuevas formas de organización parental; en los entornos mundiales donde se están experimentando cambios radicales en las formas en que se perciben y se construyen como sociedades; en las relaciones sociales, 
económicas, culturales y demás de una misma familia que comienzan a trascurrir entre dos o más fronteras nacionales (Aguirre Ochoa y Cruz Vásquez, 2013).

Ariza (2002) indica que, como muchas otras dimensiones de la vida social, el universo familiar ha sufrido igualmente el efecto de los procesos de permutación impulsados por las potencias centrifugas de la globalización. Tales transformaciones resultan más evidentes en las unidades familiares inscritas parcial o totalmente en los circuitos migratorios internacionales, aunque no solo en ellas. La migración ha dado lugar a la conformación de un espacio social inédito -espacio de la transnacionalidad-, el de los intensos lazos y vínculos sociales que integran a los que se desplazan y a los que se quedan en una estructura intangible de densas redes de comunicación -instrumentales y simbólicas- entre dos o más países (Faist, 2000).

El peso de la familia en la organización de la vida cotidiana de los migrantes es un correlato natural de la situación de extrañamiento y desterritorialización que produce la migración. Ubicados fuera de la comunidad y el país de origen, los migrantes echan mano de las pautas y secuencias básicas de la vida familiar para introducir orden en sus vidas y responder con algunas certezas a los desafíos planteados por el contexto de inserción. (Ariza, 2002, p. 62).

La centralidad de la familia desciende de dos aspectos interconectados: es uno de los primordiales ejes de ordenación de la vida de los migrantes en los territorios de destino (Malkin, 1999); asimismo, establece un foco determinante en el significado que los migrantes atribuyen a la experiencia de migrar y a otras vivencias sociales (Ariza, 2000; Malkin, 1999).

La relación entre los conceptos de migración y familia es planteada como una relación de permutación (Izquierdo Marín y Bonilla Vélez, 2010). Vista de esta forma, la migración internacional es percibida como una estrategia familiar (Díaz, 2009) y una oportunidad que facilita el acceso a recursos, vía remesas familiares, con los cuales se suplen requerimientos de subsistencia (alimentación, educación, salud, abrigo) individuales y de grupo y se generan nuevas dinámicas en la crianza y cuidado a través de la red familiar (abuela, madre, tía) como soporte material y afectivo (Izquierdo Marín y Bonilla Vélez, 2010).

Por todo lo anterior, algunos autores han planteado conceptualizar a la familia como una serie de relaciones o una red social de individuos atados por un parentesco definido por el entorno (Freire, 2004; Mora, 2008). Esta enunciación permite pensar la diferencia entre hogar y familia y acentuar que las relaciones familiares pueden ampliarse $y$ persistir a través del tiempo, a pesar de las separaciones físicas de corta o larga duración (Landolt, 2006; Velasco Ortíz, 2014).

\section{EMIGRACIÓN: EL CASO VENEZOLANO}

Venezuela es un país que en su historia de conformación patriótica y sociopolítica nunca había estado acostumbrado a los procesos de emigración social, es un Estado sin tradición de migración (Rivas, 2011; Mateo y Ledezma, 2006). Los diferentes estudios revisados señalan que este país ha sido una 
nación donde gran cantidad de personas provenientes del continente europeo y del sur de América llegaron a vivir en las décadas de 1930 y 1970 debido a las dos guerras mundiales, a la Guerra Fría y sobre todo al auge que generó la bonanza económica producto de la política extractivista del petróleo (Lugo, 1998; Delgado y Abellana, 2009; de Flores, 2017). Venezuela ha sido durante la mayor parte del siglo XX, junto a otros países latinoamericanos como Argentina, un país de recepción de inmigrantes: millares de personas llegaron huyendo a mediados del siglo pasado, de un sur de Europa devastado por guerras, dictadores y pobreza, y luego de una América Latina empujada por dictaduras militares, crisis económicas y explosiones demográficas (Cosio-Zavala, 1998). Pero a partir de la década de los ochenta, Venezuela se sumergió, junto al resto del continente latinoamericano, en una grave crisis económica, social y política, con la que cerró el siglo XX, llena de ofrecimientos de cambio e igualdad social.

El período de inflexión de los años ochenta, la nombrada década perdida, que Venezuela abrió con el cataclismo monetario del "Viernes Negro" y cerró con el bombazo social del "Caracazo" (Pellegrino, 1989), tendría sus consecuencias en la realidad migratoria del país, Venezuela empezaría a dejar de ser ese gran polo de inmigración que fue durante buena parte de la segunda mitad de siglo $\mathrm{XX}$, como reflejan los censos (Lugo, 1998) y el saldo migratorio del país desde entonces.

La masiva corriente migratoria latinoamericana que comprendió la segunda mitad del siglo XX coincide con crisis sociales, económicas y políticas, con discrepancias según cada historia nacional. La cuestión de Venezuela es, como la de los demás países, única -aunque en algunas ocasiones con aspectos similares- y los estudiosos del tema han construido diferentes versiones o formas de contar esta historia. Algunos investigadores lo han sintetizado, recalcándolo en el origen de las invariancias de un "Estado mágico" petrolero, agente modernizador y mito de riqueza colectiva, que ha dejado sin resolver urgentes problemas sociales, evidentes antes del año 2000 y a partir de entonces componente progresivo de segmentación social y política (Carreño, 2013). Para el caso venezolano, la inconmensurable emigración surgida en el país, se da por las permutaciones en la estructura del Estado, que han llevado a que el Gobierno tenga que replantear el modelo económico de la sociedad (Echeverry, 2012), lo que ha generado contrariedades de interés entre los disímiles grupos sociales establecidos por extensos años en el país.

Algunas investigaciones revisadas dejan entrever que durante los años ochenta y noventa Venezuela dio un vuelco transcendental en sus patrones migratorios. La severa crisis en la que se sumergió el país no solo tuvo efectos desalentadores sobre los movimientos migratorios provenientes del exterior, sino que, adicionalmente, contribuyó a desencadenar procesos de retorno de los extranjeros que habitaban el país suramericano y la emigración de venezolanos, quienes también reaccionaron frente a ese contexto de recesión económica, descomposición social y deterioro institucional (Freitez, 2011; Ruiz Meneses, 2017). Sin embargo, es durante la última década que, al parecer, esta dinámica se acrecienta. En su retentiva económica, social o política, 
la nación venezolana no tenía la experiencia de la emigración internacional, aquella que implica el abandono del lugar de origen por un período de tiempo prolongado $\mathrm{o}$ indefinido.

Siguiendo por esta senda, parte de los estudios revisados plantean que, en la última década, el debate público en torno a la experiencia migratoria de los venezolanos revela el enfrentamiento de dos posturas. La primera apunta a la denuncia de la "fuga de cerebros" (Vega, 2003; Requena y Caputo, 2016; De La Vega y Vargas, 2017); mientras que, desde la perspectiva contraria, el acto migratorio supone la renuncia y consecuente "traición a la patria" (Valladares-Ruiz, 2012 y 2013). En la encrucijada entre una y otra postura se puede prestar cuidado, por una parte, al carácter de miradas desplazadas -afligidas- del país de origen en el encuadre de los cambios sociales, económicos y políticos que ha desatado la llamada "revolución bolivariana" y, por la otra, al procedimiento literario de sujetos carentes, segregados y alienados por la propagación de la política nacional.

Si bien la escritura de procesos migratorios en la literatura venezolana contemporánea se había concentrado casi exclusivamente en la inmigración, en los últimos años asistimos al frecuente apogeo de narraciones sobre sujetos emigrantes que concuerdan con el éxodo masivo de venezolanos de la última década (Romero, Rondón y De Abreu, 2016; Castillo Crasto y Reguant Álvarez, 2017; Allen González y Fazito, 2018; Clark, 2011; García Castro, 2007; Posada Calle, 2017; Dekocker, 2017; Ruiz Méndez, 2018; Parra Calderón, 2017). La migración, un asunto que según varios estudios ha ido en aumento en la última década, ha conllevado a la salida de venezolanos hacia distintos países del mundo, especialmente Estados Unidos y España y los países latinoamericanos (Iturralde, 2014; Ochoa, 2012), en su mayoría por las dificultades económicas, políticas y sociales por las que atraviesa el país. Sin embargo, también debe tenerse en cuenta que en la decisión de emigrar intervienen factores personales y circunstancias particulares de los sujetos.

Hablar de Venezuela es una cuestión de noticia actual debido a las transformaciones sociales, económicas y políticas que han tenido cabida en ese país en los últimos tiempos, permutaciones que no solo han impactado el quehacer doméstico, sino también en la región y más allá del continente, y entre los cuales, la emigración es un aspecto de importancia histórica y coyuntural.

En algunos de los estudios revisados se plantea que, con el ascenso al poder del teniente coronel Hugo Chávez Frías desde 1999 acompañado del controversial cambio constitucional que llevó a la implantación en Venezuela del llamado socialismo revolucionario del siglo XXI (Requena y Caputo, 2016), se favoreció el incremento del proceso migratorio venezolano, ya que la emigración era un proceso que se presentaba de manera muy esporádica - pues los venezolanos consideraban que su nivel de vida futuro no estaba en riesgo- a lo que se le añade que el cometido gubernamental del mandatario generó en los ciudadanos de clases media y alta un sentimiento de amenaza en cuanto a la seguridad e integridad de sus intereses, por lo cual optaron por huir a otro país (Guardia, 2007). Este acontecimiento, sin embargo, se se incrementó en el período 
presidencial 2013-2018, entre otras circunstancias, por una crisis, además de económica y política, de tipo social e institucional que ha generado un cambio en las pautas migratorias de los originarios de ese país, quienes se habían diferenciado del resto de América del Sur por una baja propensión a migrar al exterior.

Con la llegada de Nicolás Maduro al poder en Venezuela, tras la muerte del presidente Hugo Chaves, se agudizó la situación socioeconómica por la que venía atravesando este país, presentándose una de las crisis migratorias más grandes en Venezuela, incrementándose la emigración de venezolanos a Colombia y el retorno al país de miles de colombianos que se habían radicado en el vecino país, en busca de mejores oportunidades. (Ruiz Meneses, 2017, p. 9).

Muchos de los estudios, en su generalidad periodísticos, de la creciente ola migratoria venezolana se esfuerzan en ligar este proceso a las transformaciones sociopolíticas que ha implantado e impulsado - según cómo se mire- la revolución bolivariana. El desencanto, la incertidumbre por el futuro, la violencia, la falta de proyectos colectivos, la precariedad del presente, son temas que atraviesan buena parte de la narrativa del siglo XXI (Rivas, 2013), cuando comenzó a producirse la migración de jóvenes en busca de mejoras en su situación económica, debido a la aguda crisis económica que hizo quebrar a varios bancos, al desempleo y el subempleo, al vacío político y a la falta de horizontes para la juventud (Rivas, 2011).

La investigadora Lorena Cecilia Mena Iturralde en un estudio etnográfico titulado
“Evolución de los procesos adaptativos de los migrantes venezolanos radicados en Monterrey de 1978 a 2010", muestra que los motivos de desplazamiento expresados por los entrevistados venezolanos, en especial de la década reciente, tienen relación con la expectativa de una mejor calidad de vida y con la crisis sociopolítica de Venezuela, pues indican que se mudaron a Monterrey debido a que su país no es el mejor lugar para vivir. Así, la crisis no es percibida solo como política, sino como una crisis cultural, educativa, laboral, económica y hasta de valores (Iturralde, 2014). A ello se le suma que la realidad que afronta el emigrante es muy complicada. Por una parte, el proceso de establecimiento en la sociedad de destino debiéndose ajustar a diferentes costumbres, la relación en sociedades donde el rechazo al extraño llega inclusive a desatar maneras violentas. Por otra parte, la emigración transforma la mirada que se tiene del país de origen. La literatura sobre el tema concuerda en destacar las dificultades de identidad que vive el emigrante, sobre todo cuando procede de un país colonizado lleno de diversidad cultural como el venezolano.

Aunque se conocen las diferentes clasificaciones de los migrantes -refugiados, asilados, inmigrantes, emigrantes, irregulares e indocumentados- y se registra su importancia, la emigración se entiende como el desplazamiento por diversos motivos de hombres y mujeres de un país a otro. Dentro de este desplazamiento surge la concepción de lo que se viene conociendo como la narrativa de la diáspora venezolana, entendida como suceso aún naciente, sobre todo cuando se coteja con las literaturas de otros países latinoamericanos. 
Es un acontecimiento novedoso sujeto por tanto a cambios aún impredecibles, pero la diáspora misma es algo en constante transformación. Pensar que una literatura diaspórica es la misma literatura de la nación donde se originó, pero realizada lejos de ella, es una simplificación (Carreño, 2013). La diáspora se conforma como una contestación a las dificultades de la nación -en este caso la venezolana- pero asimismo como una oportunidad de compensación e influencia cultural más allá de las fronteras nacionales. Una de las particularidades de la diáspora es su constante oscilación, su falta de teleología. Esto puede generar resistencias moderadas o intercambios, contactos y mestizajes con los otros, pero que escapan a un centro, promoviendo historias (narrativas) convergentes y divergentes al mismo tiempo.

Por otra parte, la creciente globalización de la economía ha tenido un fuerte impacto en la migración internacional. Se estima que al menos 175 millones de profesionales viven fuera de su país de origen y que, de ese número, 65 millones son económicamente activos (Hernández y Ortiz Gómez, 2011). En línea con esto y como lo registran la mayoría de estudios consultados, la generalidad de la población emigrante de Venezuela son profesionales universitarios, pertenecientes a la clase media y alta de la sociedad venezolana, muchos con títulos de posgrado, en cuya educación los países de recepción no han tenido que invertir, de modo que se trata de una transferencia de riqueza desde el país de origen. La emigración de venezolanos ha venido creciendo particularmente en los estratos medios de la población y entre las razones más frecuentes para dejar el país se han identificado: el hecho de no visualizar oportunidades de desarrollo individual y la inseguridad personal (Latinos Globales, 2008; Mateo y Ledezma, 2006; Ibarra y Rodríguez, 2010). Sin embargo, en una de las investigaciones revisadas se plantea que el perfil socioeconómico del ciudadano venezolano ya no es únicamente el de clase media-alta, por el contrario,

[...] en los últimos tres años y a comienzos de este año 2017, la cifra de ingresos se ha disparado, convirtiéndose en un tema humanitario porque están llegando venezolanos con pocos recursos y debido a la falta de oportunidades han tenido que recurrir a cometer delitos o ejercer la prostitución para poder sostener a sus familias. (Ruiz Meneses, 2017, p. 10).

Ello sucede ya que en los países de América Latina -y Venezuela no es la excepción-hay contrariedades estructurales que permanecen y cuya tramitación no se indica en el corto plazo, dentro de las cuales se encuentran la vulnerabilidad de la economía, la poca generación de empleos formales y las deficiencias en los servicios públicos, entre otros, que entristecen las posibilidades de imaginar un futuro mejor. Así pues, emigrar es algo más que la búsqueda de oportunidades económicas, de un trabajo, es también la búsqueda de un contexto seguro que permita el desarrollo de la simple vida cotidiana (Freitez, 2011).

El incremento notable de la emigración desde Venezuela es comparativamente reciente y no prevalecen las indagaciones ni las fuentes nacionales de pesquisa que permitan instituir con mediana claridad las existencias de los originarios de este país que han partido a residenciarse en el exterior y cuáles son 
sus características. Sin embargo, en varios estudios de caso, se ha podido encontrar que en América Latina la crisis económica de la década de los ochenta y sus repercusiones a comienzos el siglo XXI, empujaron a su población primero hacia Estados Unidos y luego hacia España y otros países como Canadá, Japón, Australia o Inglaterra.

No se tiene certeza acerca del número de venezolanos que en los últimos diez años se han trasladado a Estados Unidos... La simple circunstancia de señalar extraoficialmente que más de trescientos mil venezolanos viven en Estados Unidos es altamente significativo habida cuenta de su existencia como fenómeno de data reciente... Las cifras oficiales del Censo del año 2000 de Estados Unidos, indican que 0.03 $\%$ de la población de este país es de origen venezolano. Oficialmente hay inscritos 91328 venezolanos en el censo, por lo cual se estima que sumando aquellos que se encuentran en situación ilegal o no hayan sido censados, la cifra podría aumentar... Desde 1998 hasta la actualidad, alrededor de unos treinta y tres mil venezolanos han recibido visas de trabajo o de residencia en Estados Unidos. Las cifras extraoficiales son abultadas, hablan de alrededor de trescientos mil venezolanos que han salido de su país en los últimos dos años. (Delgado, 2007, pp. 203-204).

Venezuela se uniría a esta ola migratoria de una forma clara a partir de mediados de los años noventa, coincidiendo con una época de alta inestabilidad económica, política y social (Inglés, 2011). Como lo plantea Ledezma, los cambios socioeconómicos y culturales experimentados por Venezuela en las postrimerías del siglo $\mathrm{XX}$ contienen entre sus múltiples expresiones, la emigración de muchos venezolanos de la clase media, que al comparar las alternativas que ofrece su país con las de otros países, optan por arriesgarse en la aventura migratoria. Los países europeos y Estados Unidos son los destinos más codiciados en este movimiento, sin embargo, no se descarta la oferta de otros países como Canadá, Australia y algunos de América Latina como Panamá y Costa Rica (Mateo y Ledezma, 2006).

Un rasgo interesante de la reciente migración internacional de los países de la Comunidad Andina es la tendencia a concentrarse cada vez más en el viejo continente, de manera especial en países como España e Italia en donde predominan migrantes andinos respecto del total de suramericanos con $59.5 \%$ y $61.2 \%$ respectivamente. (Orjuela, 2007, p. 150).

De otro lado, los procesos de migración de venezolanos a Colombia son muy recientes, si bien la relación migratoria entre ambos países se remonta a la década de los setenta cuando se inician los primeros flujos migratorios de colombianos hacia Venezuela motivados por los altos precios del petróleo. En las décadas siguientes se da un aumento de los ciudadanos colombianos residentes en el vecino país de tal manera que "las personas nacidas en Colombia pasaron de conformar la tercera parte de la población de origen extranjero en Venezuela (30.2\% en 1971) a constituir más de la mitad de esta (51.79\% en 1990)" (Reyes, 2015, p. 1). Esta historia compartida ha permitido consolidar redes sociales, económicas, institucionales y familiares entre ambos países que posiblemente 
ahora estén sirviendo para que el flujo se dé en la dirección contraria.

En este sentido, según datos de Migración Colombia el número de ciudadanos venezolanos que han ingresado al país en los últimos años ha venido en crecimiento, de tal manera que para el año 2014 entraron a Colombia 275965 venezolanos, para el 2015 esta cifra aumentó a 329466 y para 2016 se llegó a un número de 378948 migrantes. Durante el 2015 y 2016 no se evidencia un aumento significativo en el número de entradas de venezolanos a territorio colombiano, y esto se puede deber a que en agosto del año 2015 el Gobierno venezolano decretó el estado de excepción en la región fronteriza del estado de Táchira, el cual para finales del mismo mes se extendería a otros estados venezolanos limítrofes con Colombia. Sin embargo, en el año 2017 la cifra de migrantes venezolanos que ingresó a Colombia fue de 769 012, duplicándose el número de personas que llegaron al país en comparación con el año inmediatamente anterior.

Los datos más recientes sobre el proceso migratorio de los venezolanos a Colombia sostienen que "al 30 de septiembre del 2018, Colombia contaba con aproximadamente 1 032016 migrantes regulares e irregulares desde Venezuela residiendo en su territorio" (Conpes, 2018, p. 14).

El resultado de la dinámica migratoria de los latinoamericanos -en este caso de los venezolanos- es complicada y las diferentes teorías que tratan de exponerla suelen incluir variables tales como transición demográfica, globalización de los medios de comunicación, dependencia cultural, estrategias socioculturales y redes familiares. El rigor de la emigración en los diversos países de América Latina se enlaza con los aprietos de progresión que estos han experimentado, los cuales tienen expresiones negativas sobre los niveles de vida, el desempleo, la reducción del salario real y la inseguridad económica, en consecuencia constituyen estímulos para que las personas tiendan a abandonar sus países de origen. Luz Marina Rivas nos dice que en estos primeros años del siglo XXI, cuando Venezuela ha conocido un éxodo inédito en su historia, siendo un país sin tradición de migración, la ficción recoge la pregunta: ¿irse o quedarse?, pregunta que tantos venezolanos se hacen (Rivas, 2011). Estas narrativas no trazan tanto la vida más allá de los confines sino el resquicio entre un espacio y otro, este, que ya no concierne, y aquél, que jamás nos concernirá.

\section{Conclusiones}

Podríamos plantear que el aumento de los movimientos migratorios en el mundo $-\mathrm{y}$ sobre todo en Latinoamérica- desde finales del siglo XX es un efecto esperado de la globalización (Muñoz Jumilla, 2002). Partiendo de la revisión documental realizada, en lo concerniente al caso venezolano, encontramos que, aunque el estudio de la migración se ha centrado en su mayoría en los estudios de inmigración en los últimos veinte años, los estudios sobre la emigración venezolana han ido aumentando de forma exponencial. En ellos podemos ver cómo le emigración a generado el desplazamiento de personas y familias de un contexto cultural a otro, concentrando una cadena de narraciones que registran la transformación de las redes sociales, culturales e identitarias, las necesidades económicas, la xenofobia, el racismo y la construcción de un espacio liminal que 
ocupan los venezolanos llegados en la sociedad de recepción.

Por otra lado, hemos podido ver cómo la familia -en su expresión objetiva como eje estructurador de la vida social y modeladora de los vínculos sociales de parentesco que suministran el sentido de continuidad y constancia de los migrantes con sus territorios de origen, y en su extensión subjetiva como, territorio de anclaje y foco central en la definición de sentimientos que consuman los migrantes en sus narraciones personalesforma una posición social de trascendental importancia en el ambiente emergente de la emigración.

En efecto, en un entorno social fracturado por tensiones ideológicas, socioeconómicas y raciales, el proceso migratorio se erige en algunas ocasiones, como una herramienta de transformación y -en el mejor de los casos- de superación personal (Valladares-Ruiz, 2012). Finalmente, el análisis de la emigración venezolana abre la puerta para conocer sobre la práctica migratoria y la edificación de un "territorio otro" como lugar oportuno para la controversia de las identidades nacionales y para la escritura de las relaciones entre sujetos migrantes y sus entornos socioculturales.

\section{REFERENCIAS}

Aguirre Ochoa, J. y Cruz Vásquez, M. (2013). Familia y migración. Ra Ximhai, 9(2).

Allen González, A. J. y Fazito, D. (2018). Dinámica de cambio en las redes sociales y la formación de vínculos transnacionales: un caso de venezolanos profesionales viviendo en París. Redes.
Revista hispana para el análisis de redes sociales, 29(1), 44-64. DOI: https://doi. org/10.5565/rev/redes.370

Ariza, M. (2000). Ya no soy la que deje atrás: mujeres migrantes en República Dominicana. Santo Domingo, República Dominicana: Plaza y Valdés. DOI: https://doi. org/10.2307/3541396

Ariza, M. (2002). Migración, familia y transnacionalidad en el contexto de la globalización: Algunos puntos de reflexión. Revista Mexicana de Sociología, 53-84. DOI: https://doi.org/10.2307/3541596

Carreño, V. (2013). Apuntes para una narrativa de la diáspora venezolana: enfoques, tendencias y problemas. INTI, (77/78), 93-104.

Castillo Crasto, T. y Reguant Álvarez, M. (2017). Percepciones sobre la migración venezolana: causas, España como destino, expectativas de retorno. Migraciones. Publicación del Instituto Universitario de Estudios sobre Migraciones, (41), 133163. DOI: https://doi.org/10.14422/mig. i41.y2017.006

García Castro, A. A. (2007). Inmigración, ideología y medios de comunicación en Venezuela. En Imaginarios del otro: realidad y percepción del fenómeno migratorio a través de los medios de comunicación (pp. 21-37). Burgos, España: Editorial Gran Vía. DOI: https://doi. org/10.6035/2174-0992.2018.16.11

Consejo Nacional de Política Económica y Social - Conpes. (2018). Estrategia para la atención de la migración desde Venezuela.

Checa, F. (ed.). (2002). Las migraciones a debate: de las teorías a las prácticas sociales. 
Barcelona, España: Institut Català d'Antropologia.

Clark, F. (2011). La política petrolera venezolana y su vinculación con el aumento en la emigración de recursos humanos calificados (Tesis de Maestría). Buenos Aires, Argentina: Flacso. Sede Académica Argentina, Universidad de San Andrés, Universitat de Barcelona. DOI: https:// doi.org/10.25145/j.pasos.2017.4.009

Cosio-Zavala, M. E. (1998). Changements démographiques en Amérique latine. París, Francia: De Boeck Secundair.

Cozzani, M. R. e Insa, C. (2011). Redes y procesos transfronterizos en migraciones internacionales recientes. Revista de Historia de América, 29-46.

de Flores, R. Á. (2009). Refugiados entre fronteras: La nueva realidad migratoria colombo-venezolana. Observatorio Laboral Revista Venezolana, 2(4), 2.

de Flores, R. Á. (2017). Evolución histórica de las migraciones en Venezuela. Breve recuento. Aldea Mundo, (22), 89-93.

De La Vega, I. y Vargas, C. (2017). La intención de emigración de estudiantes universitarios. Estudio comparado en cuatro universidades venezolanas. Interciencia, 42(12), 798-804.

Delgado de Smith, Y. (2007). Migración desde la perspectiva de género: el caso venezolano. Retos de la Migración Latinoamericana, 195-215.

Delgado de Smith, Y. y Abellana Chaybub, M. R. (2009). Venezuela y migración: el trabajo como agente de cambio. Anuario $n .^{o}$ 32. Recuperado de http://servicio.bc.uc.edu.ve/derecho/revista/idc32/ art8.pdf

Dekocker, K. M. (2017). La emigración venezolana como estrategia de reproducción social y su concreción en España entre 1998-2015: factores determinantes (Tesis de doctorado). Universidad Pontificia Comillas, Madrid, España.

Di Brienza, M. (1997). Población y migraciones. Revista SIC, 60(600), 474-479.

Díaz, L. M. (2009). La construcción de redes sociales y su impacto en las migraciones. Diálogos Migrantes, 3, 8-18.

Echeverry Hernández, A. A. (2012). Análisis de la migración venezolana a Colombia durante el gobierno de Hugo Chávez (1999-2011). Identificación de capital social y compensación económica. Revista Análisis Internacional, 1(4), 33-52.

Faist, T. (2000). The volume and dynamics of international migration and transnational social spaces (No. 304.8 F3). Oxford Scholarship Online.

Freire, G. (2004). Migraciones rurales andinas: un estudio a ambos lados de la frontera colombo-venezolana. Boletín Antropológico, 22(62).

Freitez, A. (2011). La emigración desde Venezuela durante la última década. Revista temas de coyuntura, (63).

Guardia Rolando, I. (2007) Fuga de venezolanos durante la Revolución Bolivariana (1998-2007). Investigaciones geográficas, (44), 187-198. DOI: https://doi. org/10.14198/ingeo2007.44.10

Hernández, T. y Ortiz Gómez, Y. (2011). La migración de médicos en Venezuela. Revista Panamericana de Salud Pública, 30, 177-181.

Ibarra, M. y Rodríguez, C. (2010). ¿Por quése van? El fenómeno migratorio de Venezuela hacia Australia desde la mirada del futuro migrante calificado (Doctoral dissertation, tesis de grado). Universidad Católica Andrés Bello, Caracas, Venezuela.

Inglés, E. P. (2011). La emigración venezolana rumbo a España: características 
socio-demográficas e inserción laboral de una migración latinoamericana en tiempos de crisis. Revista Temas de Coyuntura, (63).

Iturralde, L. C. M. (2014). Los otros inmigrantes. Identidades y diferencia en la integración cultural de los venezolanos residentes en Tijuana (tesis de maestría). El Colegio de la Frontera Norte, Tijuana, México. DOI: https://doi.org/10.17711/ sm.0185-3325.2018.025

Izquierdo Marín, D. F. y Bonilla Vélez, G. E. A. (2010). Migración, transnacionalismo y familia. Caso Colombia-Venezuela. Universidad de Cartagena, Colombia.

Landolt, P. (2006). Modernidad tardía y migración transnacional: reflexiones conceptuales desde el caso de El Salvador. Colombia: Migraciones, transnacionalismo y desplazamiento. Bogotá D. C., Colombia: Universidad Nacional de Colombia. DOI: https://doi.org/10.18273/revsal. v50n3-2018008

Lucena, H. (2007). Lo laboral en tiempos de transición. Carabobo, Venezuela: Universidad de Carabobo.

Lugo, I. (1998). Venezuela: un examen de la migración internacional en la comunidad andina usando datos censales. Santiago de Chile, Chile: Cepal.

Malkin, V. (1999). La reproducción de relaciones de género en la comunidad de migrantes mexicanos en New Rochelle, Nueva York. Fronteras fragmentadas, 475-96.

Martínez Casadiegos, D. C. (2016). El proceso migratorio entre Colombia y Venezuela (1989-2014): principales causas y efectos políticos para la integración entre ambos países (tesis de maestría). Universidad Católica de Colombia, Universitá Degli Studi di Salerno, Italia. DOI: https://doi.org/10.14718/culturalatinoam.2017.26.02.8

Mateo, C. y Ledezma, T. (2006). Los venezolanos como emigrantes. Estudio exploratorio en España. Revista venezolana de análisis de coyuntura, 12(2), 245-267.

Mora, C. (2008). Globalización, género y migraciones. Polis. Revista Latinoamericana, (20). DOI: https://doi.org/10.4067/ s0718-65682008000100015

Muñoz Jumilla, A. R. (2002). Efectos de la globalización en las migraciones internacionales. Papeles de población, 8(33), 9-45.

Ochoa, W. M. (2012). Colombia y las migraciones internacionales. Evolución reciente y panorama actual a partir de las cifras. REMHU-Revista Interdisciplinar da Mobilidade Humana, 20(39), 185-210. DOI: https://doi.org/10.1590/ s1980-85852012000200010

Orjuela, N. F. (2007). La migración internacional de los países de la Comunidad Andina. Retos de la Migración Latinoamericana, Flacso, 139-154. DOI: https:// doi.org/10.2307/j.ctv3dnp14.15

Oso Casas, L. y Villares Varela, M. (2005). Mujeres inmigrantes latinoamericanas y empresariado étnico: dominicanas en Madrid, argentinas y venezolanas en Galicia. Revista Gallega de Economía, 14(1-2).

Pacheco Ríos, G. (2016). Idas y venidas: El flujo migratorio entre Colombia y Venezuela (tesis de maestría). Universidad Militar Nueva Granada, Bogotá D. C., Colombia. DOI: https://doi.org/10.18273/revsal.v49n1-2017007

Parra Calderón, S. P. (2017). Voces venezolanas en la diáspora: reconstrucción del discurso de representaciones transnacionales en notas periodísticas de blogs digitales (Tesis de pregrado). Colegio de 
Comunicación y Artes Contemporáneas, Quito, Ecuador .

Pellegrino, A. (1989). Historia de la inmigración en Venezuela siglos XIX y XX (Vol. 1). Caracas, Venezuela: Nacional de Ciencias Económicas.

Posada Calle, D. (2017). Jóvenes migrantes venezolanos en Colombia. Una mirada a sus actuales trayectorias migratorias bajo el enfoque trasnacional (tesis de pregrado). Pontificia Universidad Javeriana, Bogotá D. C., Colombia. DOI: https://doi. org/10.33304/revinv.v01n1-2013003

Requena, J., y Caputo, C. (2016). Pérdida de talento en Venezuela: migración de sus investigadores. Interciencia, 41(7).

Reyes, C. (2015). Flujo migratorio de colombianos a Venezuela: las cifras cuentan. Bogotá D. C., Colombia: Universidad del Rosario. DOI: https://doi.org/10.14482/ memor.24.6299

Rivas, N. (2004). Una invitación a la sociología de las migraciones. Barcelona, España: Edicions Bellaterra.

Rivas, L. M. (2011). ¿Irse o quedarse? La migración venezolana en la narrativa del siglo XXI. Trabajo presentado en las Jornadas de Investigación Humanística y Educativa, San Cristóbal, Venezuela, abril. DOI: https://doi.org/10.6018/ riite/2018/335131

Rivas, L. M. (2013). Migraciones íntimas: "El patio del vecino" de Raquel Rivas Rojas. INTI, (77/78), 105-113.

Romero, K., Rondón, S., y De Abreu, R. (2016). Soledad en emigrantes venezolanos. Revista Estudiantil URU, (4), 53-70.

Ruiz Méndez, J. (2018). Venezuela a la distancia: diseño de una herramienta digital que permita compilar los testimonios de la diáspora venezolana conformada entre 1999 y la actualidad para la construcción de memoria colectiva sobre este fenómeno (tesis de maestría). Universidad de La Sabana, Bogotá D. C., Colombia. DOI: https:// doi.org/10.2307/j.ctvfc52gm.5

Ruiz Meneses, C. (2017). Movimiento migratorio de venezolanos a Colombia: asentamiento de ilegales en la ciudad de Pereira (tesis de pregrado). Universidad Católica de Pereira, Pereira, Colombia. DOI: https://doi.org/10.18273/revsal. v49n3-2017004

SA, L. G. (2008). Potenciando el valor de la diáspora latinoamericana para los países de la región: estudio de las características de la emigración venezolana. DOI: https://doi.org/10.18356/32ee48d3-es

Sandell, R., Sorroza Blanco, A., y Olivié Aldasoro, L. (2007). Inmigración: ¿un desafío con oportunidades? Boletín Elcano, (92), 19.

Valladares-Ruiz, P. (2012). Narrativas del descalabro: el sujeto migrante en dos novelas de Juan Carlos Méndez Guédez. MLN, 127(2), 385-403. DOI: https:// doi.org/10.1353/mln.2012.0077

Valladares-Ruiz, P. (2013). Desplazamiento $\mathrm{y}$ disenso político en la narrativa de Eduardo Sánchez Rugeles. INTI, (77/78), 115-136.

Vega, I. (2003). Emigración intelectual en Venezuela: el caso de la ciencia y la tecnología. Interciencia, 28(5), 259-267.

Velasco Ortíz, L. (2014). Género y migración. Migraciones internacionales, 7(4), 287-291.

Villa, M., y Martínez, J. (2001). El mapa migratorio internacional de América Latina y el Caribe: patrones, perfiles, repercusiones e incertidumbres (pp. 1-28). Santiago de Chile, Chile: Cepal. 